\title{
MAHAR HAFALAN AL-QUR'AN PERSPEKTIF HUKUM ISLAM
}

\author{
1Ibnu Irawan, ${ }^{2}$ Jayusman \\ 1,2Program Pascasarjana (PPs) UIN Raden Intan Lampung \\ Jl. Yulius Usman, No.20, Labuhan Ratu, Kedaton, Bandar Lampung. 35132. \\ E-mail: whanibn@gmail.com
}

\begin{abstract}
Dowry is a gift from the bridegroom to women in the form of material, whether in the form of a set of prayer tools, rings, money or other valuables. Lately, memorization of the Qur'an is also often used as a wedding dowry, for various reasons; dowry that lightens, follows trends, and personal desires. This phenomenon is not the same as the case of Sahl bin Said al-Sa'idi. Overview of Islamic law, and the theory of maqasid al-shariyah are very appropriate to be used in determining the legal certainty of the phenomenon. This research is a literature study (library research) using descriptive analysis method.
\end{abstract}

Keywords: Dowry, Islamic Law, Memorization of the Qur'an..

\begin{abstract}
Abstrak
Mahar merupakan pemberian dari mempelai pria kepada wanita yang berupa materi, baik berupa seperangkat alat salat, cincin, uang atau barang berharga lainnya. Belakangan ini hafalan al-Qur'an juga kerap digunakan sebagai mahar pernikahan, dengan berbagai alasan; mahar yang meringankan, mengikuti tren, dan keinginan pribadi. Fenomena ini tidak sama dengan kasus Sahl bin Said al-Sa'idi. Tinjauan hukum Islam, dan teori maqasid al-syariyah sangat tepat digunakan dalam menentukan kepastian hukum dari fenomena tersebut. Penelitian ini merupakan kajian pustaka (library research) dengan menggunakan metode deskriptifanalisis.
\end{abstract}

Kata Kunci,: Hafalan al-Qur'an, Hukum Islam, Mahar.

\section{PENDAHULUAN}

Agama Islam hadir menghapuskan dehumanisasi yang dialami oleh wanita pada masa pra-Islam. Agama Islam datang dengan memperhatikan hak-hak wanita di dalam pernikahan. Termasuk hak memperoleh mahar dari pasangannya, pemberian mahar terhadap wanita yang akan dinikahi adalah salah satu bentuk memuliakan kaum wanita. Pemberian ini dapat dilakukan secara tunai berupa uang dan barang atau non tunai berupa jasa. ${ }^{1}$

1 Lili Rasyidi, Hukum Perkawinan Dan Perceraian Di Malaysia Dan Indonesia (Bandung: PT.Remaja Rosdakarya, 1991). 


\section{2 |Ibnu Irawan, Jayusman}

Mahar bukan harga bayaran² atau pengganti nilai tukar bagi wanita yang akan dinikahi. Mahar merupakan bagian dari wujud keseriusan pria terhadap calon istri yang akan dinikahi. Mahar juga berfungsi sebagai tanda ketulusan niat dari calon suami untuk membina kehidupan rumah tangga bersama calon istrinya yang ditujukan pada awal pernikahannya dengan suka rela memberikan sebagian dari hartanya kepada calon istrinya. ${ }^{3}$

Pemahaman mendasar terkait mahar pernikahan adalah sebuah pemberian dari mempelai pria kepada mempelai wanita yang berupa materi, baik berupa seperangkat alat salat, cincin, uang atau barang berharga lainnya. Namun pada prakteknya terdapat pula yang mempersembahkan mahar pernikahan berupa jasa untuk melaksanakan sesuatu. Kondisi seperti ini tidak dilarang oleh syariat Islam. Mayoritas fukaha memperbolehkannya, dengan landasan al-Qur'an dan hadis Nabi saw,. Salah satu contoh mahar pernikahan yang diberikan kepada pihak wanita dalam bentuk jasa adalah dengan mempersembahkan pengabdian dirinya selama kurun waktu 8 (delapan) tahun dengan jasanya untuk menggembala kambing yang terjadi ketika nabi Musa as, menikahi salah seorang putri nabi Syu'aib as, dengan mas kawin atau mahar berupa bekerja selama 8 (delapan) tahun, ${ }^{4}$ sejarah dan kisah tersebut Allah swt, abadikan di dalam al-Qur'an, sebagaimana yang terdapat pada QS al-Qasas Ayat 27:

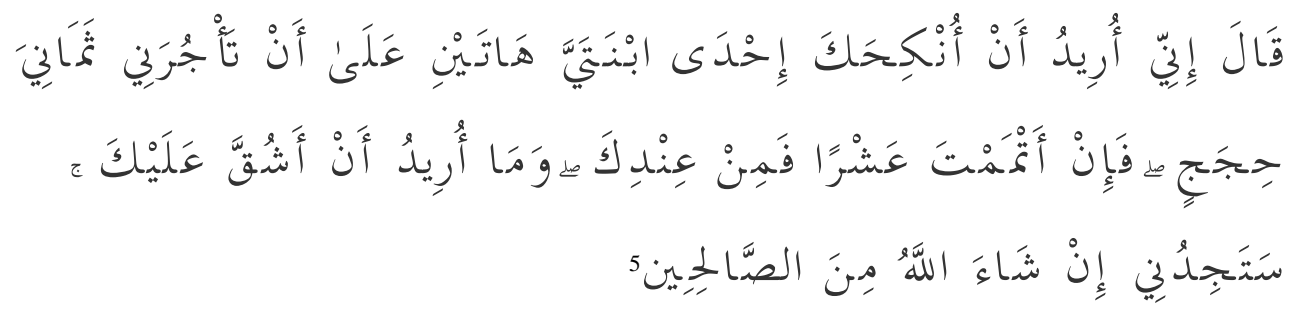

Berkatalah Dia (Syu'aib): "Sesungguhnya aku bermaksud menikahkan kamu dengan salah seorang dari kedua anakku ini, atas dasar bahwa kamu bekerja denganku delapan tahun dan jika kamu cukupkan sepuluh tahun Maka itu adalah (suatu kebaikan) dari kamu, Maka aku tidak hendak memberati kamu. dan kamu insya Allah akan mendapatiku Termasuk orang- orang yang baik".

2 Muhammad bin Ahmad bin Muhammad bin Ahmad Ibnu Rusyd, Bidayah AlMujtahid Wa Nihayah Al-Muqtasid (Beirut: Dar Ibn Hazem Li al-Tab'ah Wa Nasyr Wa Tauzi', 2006).

3 Departemen Agama RI, Ensiklopedi Islam Di Indonesia (Jakarta: Penerbit Anda Utama, 1993).

${ }^{4}$ Amir Syarifuddin, Hukum Perkawinan Islam Di Indonesia Antara Fikih Munakahat Dan Undang-Undang Perkawinan (Jakarta: Kencana Prenada Media Group, 2009).

5 Departeman Agama RI, Al-Qur'an Dan Terjemahnya (Jakarta: PT. Sinergi Pustaka Indonesia, 2012). 
Pada kenyataannya, generasi milenial banyak yang memberikan mahar pernikahan diluar kebiasaan masyarakat pada umumnya. Mahar yang di berikan bukan seperangkat alat salat, cincin, barang atau sejenisnya yang bersifat materi, akan tetapi mahar yang diberikan pada akad pernikahan adalah berupa hafalan al-Qur'an, yang dibacakan mempelai pria di majlis akad pernikahan. Sebagian masyarakat ada yang sangat menginginkan mahar pernikahan berupa hafalan al-Qur'an, dengan alasan mahar hafalan al-Qur'an dianggap lebih utama (afdal) dibandingkan dengan mahar-mahar lainnya. ${ }^{6}$ Diantara pasangan yang menikah adalah: 1) Maulana Yusuf menikahi Ghaisa Zahira dengan mahar hafalan al-Qur'an 30 juz di Bandung pada Maret 2015, 2) Munawwar Juanan Raden menikahi Dauha Muawiyah dengan hafalan 30 Juz dan hafalan 500 hadis di Damaskus pada Mei 2016, 3) Dodi Hidayatullah menikahi Auliya Rahmi Fadhilah dengan mahar hafalan surat ar-Rahman pada Juli 2011,4) Darja Wiharja menikahi Putri Diana dengan mahar hafalan surat ar-Rahman di Pare-Pare, 5) Muzammil Hasballah menikahi Sonia Ristanti dengan mahar hafalan QS al-Nisa' 34-35 dan al-Tahrim ayat 6 pada Juli 2017 di Banda Aceh, 6) M. Hurril Muhajjalin menikahi Huliyatul Jannah dengan hafalan tes hafalan al-Qur'an 30 juz yang dijadikan mahar pernikahan pada 16 Mei 2016 di Jakarta. ${ }^{7}$

Di antara tujuan atau motivasi memilih, meminta atau memberikan mahar pernikahan hafalan al-Qur'an adalah:

1. Agar sang suami menambah hafalan al-Qur'an.

2. Ingin meringankan calon suami, sebagaimana sabda Nabi saw, bahwa sebaik-baik mahar itu yang memudahkan, maka mahar hafalan al-Qur'an dianggap memudahkan.

3. Keinginan pihak wanita, karena ingin dihargai tidak sebatas materi, melainkan dengan wahyu Allah swt,.

4. Terinspirasi dari sebuah buku novel. ${ }^{8}$

Secara teori mahar hendaknya menjadi nilai manfaat dan maslahah bagi mempelai wanita. Oleh karena itu, anjuran pemberian mahar atau mas kawin berupa materi, agar kelak di kemudian hari dapat dirasakan manfaatnya, atau berupa jasa yang akan dipetik manfaat jasanya di waktu yang akan datang. Dikhawatirkan dengan pemberian mahar berupa hafalan al-Qur'an tidak sampai tujuan dari syariat pemberian mahar terhadap mempelai

6 Jusmaindah, “Empat Pemuda Ini Menikah Dengan Mahar Hafalan Ayat Al-Qur'an," accessed October 26, 2019, https://makassar.terkini.id/4-pemuda-nikah-mahar-hafalanayat-al-quran/.

7 Ibid.

8 Yayasan Qur'an Hamasah, "Alasan Mahar Nikah Hafalan Surat Al-Rahman," accessed October 20, 2018, http://hamasahtahfizhnasional.blogspot.com/2016/10/7alasan-mahar-nikah-hafalan-surah-ar.html. 
wanita serta mengabaikan esensi mahar di dalam hukum Islam. Oleh karena pemberian mahar berupa hafalan al-Qur'an kelak akan menimbulkan hilangnya hak wanita ${ }^{9}$ di dalam pernikahan, maka sebagai tindakan preventif dari persoalan ini adalah mencari hukum pasti seputar pemberian mahar berupa hafalan al-Quran.

Pemberian mahar berupa hafalan al-Qur'an juga terinspirasi oleh orang lain, sebagaimana yang dilakukan oleh pasangan Riswanto Jury dan Rosita pada tahun 2012 silam, dengan mahar pernikahan menggunakan mahar hafalan al-Qur'an, yang pemberian mahar tersebut mengikuti tren mode yang sedang berkembang saat itu di tengah masyarakat. Hal tersebut yang sangat mendorong banyak orang untuk mengikutinya dan mengidamkan kelak dirinya atau anaknya dapat mengikuti proses pernikahan yang dianggap agung jika dapat menikah bermaharkan hafalan al-Qur'an.

Pemberian mahar hafalan al-Qur'an memang baik, akan tetapi perlu ditinjau terlebih dahulu dengan prosedur hukum yang benar dan tepat, agar dikemudian hari tidak ada unsur kesalahan dan penyesalan dengan hilangnya hak-hak salah satu dari padangan suami istri.

Dari latar belakang di atas penulis mencoba mengkaji hal-hal berikut; 1) Bagaimana mahar pernikahan dalam tatanan teoritis dan hukum Islam? 2) Bagaimana fenomena yang terjadi pada masyarakat yaitu pemberian mahar pernikahan berupa hafalan al-Qur'an perfektif hukum Islam?. Dengan kajian hukum Islam ini akan menelusuri lebih dalam dan lebih lanjut bagaimana latar belakang, dorongan dari setiap pelaku, atau falsafah dari keinginan mengambil hafalan al-Qur'an sebagai mahar pernikahan. Kemudian dengan kajian hukum Islam tersebut akan menghasilkan dan melaharikan kejelasan status hukum dari fenomena tersebut.

\section{METODE}

Penelitian ini merupakan library research. Penelitian ini menggunakan pendekatan yuridis untuk mengetahui status hukum dari fenomena mahar hafalan al-Qur'an, dan pendekatan hukum Islam dalam menggali berbagai motifasi yang mendorong masyarakat menjadikan hafalan al-Qur'an sebagai mahar pernikahannya serta menakar kejelasan status hukum dari fenomena tersebut. Penelitian ini mendapatkan sumber data dari media elektronik untuk mengetahui fenomenanya dan literatur hukum yang secara spesifik membahas fikih munakahat, yang kemudian didokumentasi, diseskripsikan, dan dianalisis menggunakan pendekatan tersebut.

9 Agus Hermanto, “Teori Gender Dalam Mewujudkan Ksetaraan:Menggagas Fikih Baru," Ahkam 5 (2017): 209-230. 


\section{Mahar Pernikahan dalam Hukum Islam}

A. Konsep Mahar Pernikahan

Mahar merupakan suku kata dalam bahasa Arab, yang secara etimologi diartikan oleh kalangan pakar bahasa Arab dengan al-Atiyah ${ }^{10}$ atau al-Sadaq ${ }^{11}$ yang tidak diartikan secara harfiah saja, akan tetapi telah difahami bahwa mahar bermakna al-Atiyah atau al-Sadaq yang keduanya merupakan istilah fikih ${ }^{12}$ yang bermakna pemberian dari seorang pria untuk wanita dalam hajat akad pernikahan. ${ }^{13}$

Mahar dalam terminologi, kalangan fukaha mendefinisikan sebagai sebutan untuk suatu harta benda yang diberikan dengan tujuan pernikahan, demikian disebutkan al-Sarkhasi,14 demikian pula alNawawi ${ }^{15}$ menyebutkan dengan definisi yang serupa di atas, adapun alKasani mendefinisikan dengan sebutan al-Atiyah atau pemberian sukarela berupa materi, ${ }^{16}$ sedangkan al-Kharsi salah seorang fukaha maliki mendefinisikan mahar sebagai hak istri atas materi yang diberikan saat akad pernikahan atau setelahnya, ${ }^{17}$ sedangkan al-Syafi'i meriwayatkan bahwasaanya mahar adalah hak harta yang dilazimkan untuk diberikan atas jiwa seorang wanita, ${ }^{18}$ di dalam Kifayah al-Akhyar kitab yang menjelaskan matan Abi Syuja' diterangkan mahar adalah harta yang diberikan dari pada pria untuk tujuan pernikahan,19 al-Sinaiki menyebutkan mahar adalah imbalan atas kerelaan untuk dimiliki secara sah oleh suaminya, ${ }^{20}$ Ali al-Hasyimi menyebutkan bahwasanya mahar

10 Sa'di Abu Habib, Al-Qamus Al-Fiqhi (Damaskus: Dar al-Fikr al-Arabi, 1988).

11 Hamid Abdul Kadir, Al-Mu'jam Al-Wasit (Cairo: Dar al-Da'wah al-Alamiyah, n.d.).

12 Jamaluddin Muhammad Tahir bin Ali Al-Kajrati, Mujma' Bihar Al-Anwar Fi Gharaib at-Tanzil Wa Lataif Al-Akhbar, vol. 3 (Damaskus: Majlis Dairah al-Ma'arif al-Usmaniyah, 1967).

13 Jamaluddin Ibnu Manzur Muhammad bin Mukrim bin Ali, Abu al-Fadl, Lisan AlArab (Beirut: Dar al-Sadir, 1414).

14 Muhammad bin Ahmad bin Sahl al-Sarkhasi, Al-Mabsut (Beirut: Dar al-Ma'rifah, 1993)

15 Abu Zakaria Muhyiddin Al-Nawawi, Raudah At-Thalibin Wa 'Umdah |al-Muftin (Beirut: al-Maktabah al-Islami, 1991).

16 Alauddin Abu Bakr bin Mas'ud bin Ahmad al-Kasani, Bada'i Al-Sana'i' Fi Tartib AlSyara'i (Cairo: Dar al-Kutub al-Alamiyah, 1986).

17 Muhammad bin Abdullah al-Kharsi, Syarh Mukhtashar Khalil Li Al-Kharsi (Beirut: Dar al-Fikr al-Arabi, 1999).

18 Muhammad bin Idris bin Abbas bin Usaman bin Syafii' bin Abdul Muthalib bin Abdul Manaf al-SyaFi'i, Al-Umm (Beirut: Dar al-Ma'rifah, 1990).

19 Abu Bakr Muhammad bin Abdil Mu'min bin Hariz bin Ma'la al-Hasini al-Hishni, Kifayat Al-Akhyar Fi Halli Ghayat Al-Ikhtishar (Damaskus: Dar al-Khair, 1994).

20 Muhammad bin Ahmad Zainuddin Abu Yahya al-Sinaiki, Fath Al-Wahab Bi Syarh Minhaj Al-Tullab (Beirut: Dar al-Fikr, 1994). 


\section{6 |Ibnu Irawan, Jayusman}

dapat terhitung hutang (harta benda yang dapat ditagih) jika belum ditunaikan saat akad pernikahan, ${ }^{21}$ Wahbah Mustafa al-Zuhaili menambahkan dan melengkapi definisi sebagian lainnya dengan pemberian mahar berupa harta benda tadi bertujuan sebagai imbalan atas bercampurnya suami istri, 22 KHI menyebutkan secara lengkap terkait pengertian mahar di dalam pernikahan yaitu harta yang wajib diberikan pihak pria kepada wanita yang disepakati kadar dan ketentuannya. ${ }^{23}$

Berdasarkan berbagai definisi mahar yang telah disebutkan sebelumnya, yang bersumber dari lintas pemahaman baik lampau dan moderen, setidaknya dapat diintisarikan kepada beberapa poin penting, diantaranya: 1) mahar diberikan oleh pria, 2) mahar diberikan kepada wanita, 3) mahar berupa harta benda, 4) mahar adalah hak wanita, 5) mahar diberikan dengan tujuan pernikahan, 6) mahar diberikan dengan penuh sukarela, 7) mahar diberikan sebagai imbalan dari percampuran suami istri, dan 8) mahar ditentukan atas dasar kesepakatan.

Syarat mahar hendaknya terpenuhi beberapa hal ini; 1) mahar tersebut memiliki nilai harga, 2) mahar tersebut merupakan sesuatu yang suci, dan tidak terkategori kepada hal-hal yang bersifat najis, 3) mahar merupakan sesuatu yang bukan dari hadis gasab atau hasil mencuri, 4) mahar juga hendaknya bukan sesuatu yang tidak jelas keadaanya. ${ }^{24}$

Mengenai hikmah dari pemberian mahar, setidaknya ada beberapa hal yang dapat diuraikan;

1. Mahar pernikahan menganduk hikmah berupa diangkatnya derajat kaum wanita dengan memberikan hak kepemilikan atas sesuatu yang diberikan oleh seorang pria yang menja di suaminya pada akad nikah.

2. Pengorbanan harta yang dikeluarkan oleh pria yang dimaksudkan untuk mempersunting wanita tersebut walupun dengan mengorbankan harta yang dimilikanya.

3. Mengangkat kemuliaan dan kehormatan wanita, karena pada dasarnya seorang wanita adalah yang dicari dan dipersunting oleh pria, dengan cara mengeluarkan harta yang dimilikinya.

21 Muhammad bin Ahmad bi Abi Musa bin Ali al-Hasyimi al-Baghdadi, Al-Irsyad Ila Sabil Al-Rasyad (Muassasah al-Risalah dan Markaz al-Nakhab al-'Ilmiyyah, 1998).

22 Wahbah Mustafa al-Zuhaili, Al-Fiqh Al-Maliki Al-Muyassar (Beirut: Dar al-Kalim alThayyib, 2005).

23 Abdurrahman, Kompilasi Hukum Islam Di Indonesia (Jakarta: Academia Presindo, 1992).

24 Jabir bin Musa bin Abdul Qadir Abu Bakr al-Jaza'iri, Aisar Al-Tafasir Li Kalam AlAliy Al-Kabir (Madinah al-Munawwarah: Maktabah al-Ulum Wa al-Hikam, 2003). 
4. Menunjukan cinta dari seorang suami kepada istrinya, karena mahar bersifat pemberian dan hibah dengan sukarela, tanpa mengharap imbalan mahar yang serupa.

5. Menunjukan kesungguhan dan keseriusan diri, karena sejatinya menikah merupakan persoalan yang sangat fundamental di dalam tatanan sosial.

6. Menunjukan tanggung jawab seorang suami kepada istrinya dengan sebuah kesanggupan memberikan nafkah yang bersifat materi maupun non materi. Oleh karena itu mamperikan mahar merupakan awal mula dari berbagai hikmah yang hadir bersamaan dengan pemberian mahar di dalam pernikahan. ${ }^{25}$

B. Hukum Islam

Kata al-Hukm yang merupakan serapan dari bahasa Arab, yang kemudian digunakan menjadi kata hukum. Secara etimologis bermakna alman'u yang berarti sebuah halangan, disebutkan pula ia bermakna alQada' yang artinya keputusan, dan memisahkan untuk menghalangi kedua belang pihak yang bermusuhan. ${ }^{26}$ Sebagaimana Allah menunjukan isyarat suku kata tersebut dalam QS al-Nisa ayat 105;

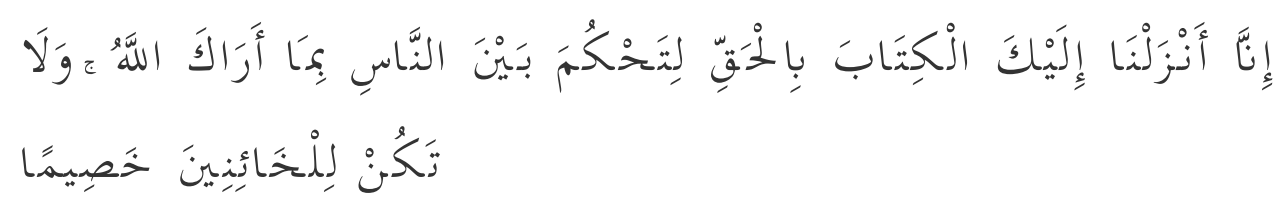

Sesungguhnya Kami telah menurunkan kitab kepadamu dengan membawa kebenaran, supaya kamu mengadili antara manusia dengan apa yang telah Allah wahyukan kepadamu, dan janganlah kamu menjadi penantang (orang yang tidak bersalah), karena (membela) orang-orang yang khianat. ${ }^{27}$

Mayoritas para ahli usul fikih menyebutkan makna secara terminologi dari hukum adalah;

25 Abd Kohar, "Kedudukan Dan Hikmah Mahar Dalam Perkawinan," Hukum Dan Ekonomi Islam, 2016, 42-50.

26 Wahbah Mustafa al-Zuhaili, Usul Fiqh Al-Islami (Beirut: Dar al-Fikr, 1986).

27 Ayat ini dan beberapa ayat berikutnya diturunkan berhubungan dengan pencurian yang dilakukan Thu'mah dan ia menyembunyikan barang curian itu di rumah seorang Yahudi. Thu'mah tidak mengakui perbuatannya itu malah menuduh bahwa yang mencuri barang itu orang Yahudi. hal ini diajukan oleh kerabat-kerabat Thu'mah kepada Nabi saw. dan mereka meminta agar Nabi membela Thu'mah dan menghukum orang-orang Yahudi, Kendatipun mereka tahu bahwa yang mencuri barang itu ialah Thu'mah, Nabi sendiri Hampir-hampir membenarkan tuduhan Thu'mah dan kerabatnya itu terhadap orang Yahudi. 
خطاب الله المتعلق بأفعال المكلفين بالاقتضاء أو التخيير أو وضع.28

Seruan atau Titah Allah yang berhubungan dengan prilaku-prilaku mukallaf (orang yang dibebani syariat) dari tuntutan atau kebolehan memilih (antara mengerjakan atau meninggalkan) atau berupa ketetapan.

Pengertian di atas dapat diintisarikan kepada tiga poin penting dari pemaknaan al-Hukm, yaitu;

1. Al-Iqtida' yang bermakna sebuah tuntutan, dalam hal ini dapat berupa tuntutan melakukan sesuatu (perintah), suatu perintah manakala ia bersifat menakan maka ia adalah wajib dan bilamana perintah tanpa penekanan maka ia sebuah keutamaan atau anjuran, atau pun tuntuta $\mathrm{n}$ untuk meninggalkan sesuatu (larangan), begitu pula larangan, manakala ia menakan maka ia terkategori haram, dan jika tanpa penekanan maka ia makruh.

2. Al-Takyir, yang bermakna sebuah pilihan, sesuatu yang dalam melakukannya ataupun meninggalkan tidak suatu ketentuan syara' yang mengatur, maka akan menjadi suatu kebebasan untuk memilih melakukan ataupun tidak atau sering disebut mubah.

3. Al-Wad'u yang bermakna sebuah peletakan, yang merupakantitah Allah swt, yang berkaitan dengan dijadikannya sesuatu sebagai sebab, syarat, larangan, sah, rusak atau rukhsah. Ia juga merupakan suatu hal yang diletakkan oleh pembuat syariat dari tanda-tanda atau sifat-sifat yang ditunaikan atau dibatalkan. Seperti suatu ibadah bisa dikatakan sah atau batal.

Hukum Islam bertujuan untuk memelihara lima masalah pokok dalam kehidupan manusia, atau berupa tujuan-tujuan hukum Islam, maqasid al-syariyah, yaitu: 1) pemeliharaan terhadap agama, 2) pemeliharaan terhadap jiwa, 3) pemeliharaan terhadap akal, 4) pemeliharaan terhadap kehormatan, 5) pemeliharaan terhadap harta. ${ }^{29}$

Setidaknya ada empat syarat dalam legitimasi sesuatu untuk diterapkan menggunakan teori maqasid al-syar'iyah; 1) bersifat tetap, dan tidak berladaskan kepada keragu-raguan atau setidaknya mendekati kepada sesuatu yang pasti. 2) bersifat jelas, sehingga tidak mengundang kepada perselisihan yang fundamental, sebagai contoh tujuan daripada perniakahan adalah agar memelihara keberlangsungan generasi umat manusia, atau disyariatkannya mahar perkawinan yang bertujuan

28 Ali Muhammad al-Amidi, Al-Ihkam Fi Ushuli Al-Ahkam (Riyad: Dar al-Shami'i Li alNasyri Wa al-Tauzi, 2003).

29 Abdul Wahab Khalaf, 'Ilmu Ushul Al-Fiqh (Cairo: Maktabah Da'wah Islamiyah, 1947). 
memuliakan dan memberikan hak kepemilikan suatu harta kepada seorang istri. 3) dapat terukur, agar dapat dimengerti dan difahami ukuran dan kadarnya sebagaimana larangan pelarangan khamr, ukurannya adalah dengan kadar memabukan atau menghilangkan kendali akal, bahwa tujuan menjaga akan merupakan hal penting di dalam agama Islam. 4) bersifat umum dan tidak ada perbedaan yang mendasar dari suatu hal pada suatu tempat atau waktu, semisal syarat seorang diperbolehkannya menjadi seorang suami dari seorang wanita adalah mampu menafkahi dan bertanggungjawab, maka mazhab maliki mendifinisikan kafaan dengan Islam saja dan ini tidak bersifat umum, melainkan khusus bagi sebagaian masyaraka saja, atau masyarakat yang hidup pada masa imam malik. ${ }^{30}$

Hukum Islam di Indonesia sendiri merujuk kepada KHI yang merupakan materi yang dapat dipedomani dalam mensikapi permasalahan atau kasus-kasus seputar hukum Islam di Indonesia. KHI turut serta memberikan aturan dalam pemberian mahar di dalam pernikahan, sebagaimana yang ditungkan dalam Pasal 1 huruf d; mahar adalah pemberian dari calon mempelai pria kepada calon mempelai wanita, baik dalam bentuk barang, uang atau jasa yang tidak bertentangan dengan hukum Islam. ${ }^{31}$

Berdasarkan pasal tersebut, dipahami bahwa mahar pernikahan merupakan pemberian wajib dari calon mempelai pria kepada seorang wanita yang akan dinikahi, yang di dalam ketegorinya dapat berbentuk barang, jasa, atau sepanjang tidak bertentangan dengan hukum Islam.

\section{Fenomena Mahar Hafalan al-Qur'an Perspektif Hukum Islam}

Mahar al-Qur'an diberikan tidak serta merta tanpa alasan dalam pemberiannya. Dialog dan wawancara telah dilakukan oleh penulis kepada masyarakat yang mahar pernikahannya adalah hafalan al-Qur'an. Proses tersebut dilakukan dan dijalankan guna mendapatkan data atas fenomena pada masyarakat yang tengah berkambang saat ini.

Motivasi yang mendorong berbagai masyarakat menikah menggunakan hafalan al-Qur'an sebagai mahar antara lain;

1. Agar sang suami menambah hafalan al-Qur'an, maksudnya adalah dengan menjadikan mahar hafalan al-Qur'an sebagai mahar pernikahan, setidaknya sang suami telah menambah kekuatan (itqan) hafalan miliknya, karena beberapa masyarakat yang menikah dengan mahar hafalan al-Quran notabenenya bukanlah dari kalangan hafiz yang telah

30 Wahbah Mustafa al-Zuhaili, Al-Wajiz Fi Usul Al-Fiqh (Damaskus: Dar al-Fikr, 1999).

31 Abdurrahman, Kompilasi Hukum Islam Di Indonesia. 
menyelesaikan hafalan al-Qur'an 30 juz, melaikan masyarakat yang menginginkan mahar hafalan al-qur'an saja.

2. Ingin meringankan calon suami, sebagaimana sabda Nabi saw, bahwa sebaik-baik mahar itu yang memudahkan, maka mahar hafalan al-Qur'an dianggap memudahkan. Sebagian masyarakat dengan hafalan al-Qur'an sebagai mahar akan terasa ringan, karena hafalan al-Qur'an yang dijadikan mahar pernikahan adalah surat yang makiah atau surat di dalam al-Qur'an yang muatan ayatnya tidak terlalu banyak dan pendek.

3. Keinginan pihak wanita, karena ingin dihargai tidak sebatas materi, melainkan dengan wahyu Allah swt, mayoritas wanita yang meminta kepada calon suami mahar pernikahannya berupa hafalan al-Qur'an adalah karena alasan ini. Mahar yang bersifat materi telah biasa dan lumrang di kalangan masyarakat. Serta jika materi atau harta benda yang dijadikan materi sebuah mahar pernikahan, maka seiring berjalannya waktu nilai dan kualitasnya tentu akan berubah atau bahkan berkurang, akan tetapi manakala hafalan al-Qur'an yang dijadikan mahar pernikahan, maka tidak akan berkurang apabila hafalan tersebut tidak dilupakannya.

4. Terinspirasi oleh sebuah novel atau public figure, selain keinginan salah satu mempelai dalam memilih sesuatu untuk dijadikan mahar, dorongan eksternal juga merupakan faktor dalam mendorong seseorang memilih hafalan al-Qur'an sebagai mahar pernikahan. ${ }^{32}$

Mayoritas masyarakat dalam menetukan hafalan al-Qur'an sebagai mahar pernikahan tidak berlandaskan kepada pemahaman fikih seputar mahar di dalam hukum Islam. sebagaimana yang telah diketengahkan di atas, beberapa latar belakang yang mendorong seseorang menajadikan hafalan al-Qur'an sebagai mahar adalah tidak berlandaskan kepada aspek hukum Islam. Keinginan pribadi, kesederhanaan, dan faktor eksternal lain yang justru mendasari untuk menjadikan hafalan al-Qur'an sebagai mahar di dalam pernikahan.

Prinsip hukum Islam sebagaimana diterangkan di atas dalam pemeliharaan terhadap kehormatan manusia. Aspek hikmah dari pemberian mahar sangat mendasar manakala dikaji secara komprehensif, kareya sejatinya mahar perniakahn merupakan sesuatu yang diberikan kepada seorang istri yang bertujuan untuk memuliakan dan menghormati wanita

32 Data di dapat dari hasil dialog dan wawancara Ahmad Taufik Ramadhan domisili Kendari, M Susanto domisisli Bandar Lampung, Amanaturrahman domisili Palembang, Rindang Susanto domisili Lampung Selatan, Zainuddin domisili Pesawaran, Arniza domisili Ogan Ilir, Ahmad Wajdi Nakib domisisli Jakarta, Ahmad Chairuddin domisili Depok dan Ahmad Khairul Fikri domisili Banten, wawancara via telephone pada Oktober 2018 sd Juli 2019. 
yang akan dijadikan istri. Oleh karena itu, di dalam aturannya, pemberian mahar pernikahan hendaknya membawa asas manfaat untuk istri, agar seorang wanita merasa dihormati dan dimuliakan dengan pemberian tersebut.

Hafalan al-Qur'an yang dijadikan mahar di dalam pernikahan merupakan sebuah upaya untuk merefleksikan tujuan syariat Islam itu sendiri. Pemeliharaan kehormatan seorang wanita dengan cara memberikan mahar yang diperintahkan oleh agama Islam kepada wanita berupa hafalan al-Qur'an. Mahar tersebut secara konten dan materi tidak dapat dibuktikan dengan kadar maupun bentuk, akan tetapi secara abstrak dan keyakinan dapat dirasakan langsung oleh mempelainya, yaitu dengan memberikan mahar berupa hafalan al-Qur'an pasangan suami istri merasakan ikhlas menerima pasangan, suasana islami dan tentunya sakinah mawadah warahmah.

Aspek tanggung jawab merupakan dasar dari pemberian mahar berupa hafalan al-Qur'an. Karena mayoritas mahar dengan hafalan al-Qur'an adalah permintaan dari calon mempelai wanita, yang disanggupi oleh mempelai pria. Adakalanya memberikan mahar berupa hafalan al-Qur'an tidak mampu oleh kalangan masyarakat lainnya, akan tetapi sang wanita menawarkan, dan mungkin tahu bahwasannya calon suaminya memeliki kemampuan untuk memberikan hafalan al-Qur'an sebagai mahar pernikahan. Seseorang yang tidak fasih dalam membaca al-Qur'an mungkin akan menolak untuk memberikan mahar berupa hafalan al-Qur'an, karena memang tidak mampu, maka bisa saja mahar dengan kategori tersebut tidak dapat dilaksanakan dan diganti dengan mahar yang umum pada masyarakat. Maka dengan penuh tanggung jawan seorang pria yang mampu memberikan mahar penikahan dengan hafalan al-Qur'an yang dimilikinya merupakan bentuk dari tanggung jawabnya merefleksikan tujuan dari syariat Islam.

KHI pasal 1 huruf b di dalam menerangkan hukum dan aturan mahar terasa longgar, disebutkan mahar hendaknya berupa benda atau jasa atau sesuatu hal yang tidak bertentangan dengan hukum Islam. Aturan ini merupakan prinsip yang baik dan layak untuk diimplementasikan dalam permasalah mahar pernikahan, karena dasar yang dibangun adalah mahar hendaknya tidak bertentangan dengan hukum Islam. Sebagaimana telah disebutkan dalam syarat mahar adalah membawa manfaat, manakala mahar tersebut terlihat mewah dan mahal akan tetapi tidak mengandung unsur manfaat maka mahar tersebut juga tidak dapat dibenarkan. Mahar sederhana sebagaimana yang dianjurkan oleh Nabi saw, dan membawa manfaat bagi seorang wanita itulah yang justru sangat dianjurkan.

Mahar hafalan al-Qur'an sebagaimana yang dituturkan oleh berbagai narasumber adalah sebuah upaya yang diharapkan manfaatnya kelak di 


\section{2 |Ibnu Irawan, Jayusman}

waktu menjalai kehidupan rumah tangga. Sehingga hafalan al-Qur'an tersebut memberikan dampak positid tehadap kehidupan rumah tangga yang; 1) dekat dengan al-Qur'an; 2) senantiasa di dalam naungan al-Qur'an; 3) manjadi ahlu al-Qur'an yang selalu membaca, mentadaburi, mempelajari, dan mengamalkan al-Qur'an; 4) mahar yang dinilai merupakan mahar yang bersifat ukhrawi dan tidak hanya dapat dirasakan di dunia saja.

Penjelasan KHI Pasal 1 huruf b mahar dalam bentuk benda, uang, dan jasa. Mahar hafalan al-Qur'an terasa mustahil manakala dipadankan dengan benda atau uang. Akan tetapi mendekati kepada persamaan antara mahar hafalan al-Qur'an dan mahar jasa. Mahar jasa dalam fikih Islam adalah diperbolehkan. ${ }^{33}$ Hafalan al-Qur'an yang dibacakan mempelai pria pada akad nikahnya merupakan proses tarbiah dan mendidik keluarganya kepada keluarga qurani. Seorang yang fasih membaca al-Qur'an di dalam kehidupannya akan rutinmembaca, memahami, mengkaji, dan mengamalkan al-Qur'an. Karena itu proses tersebut secara tidak langsung dapat dikategorikan kepada mahar jasa yang diberikan kepada istrinya berupa pengajaran al-Qur'an. Lembaga fatwa kerajaan Arab Saudi memberikan fatwa yang menerangkan diperbolehkan memberikan mahar berupa pengajaran al-Qur'an dan melarang mahar berupa hafalan al-Qur'an;

$$
\text { يصح أن يجعل تعليم المرأة شيئا من القرآن مهراً لها عند العقد عليها إذا لم يجد مالا.34 }
$$

Diperbolehkan menjadikan pengajaran al-Qur'an diberikan kepada seorang wanita sebagai mahar pernikahannya jika tidak memiliki harta benda.

Pandangan berbagai tokoh agama di Indonesia terkait kebolehan pemberian mahar pernikahan menggunakan hafalan al-Qur'an turut hadir, sebagian memperbolehkan mahar pernikahan berupa hafalan al-Qur'an dengan alasan mahar tersebut adalah kalamullah, mahar terbaik dan lebih utama, serta pembolehannya asalkan seorang pria tersebut benar-benar memiliki hafalan al-Quran, tidak dengan rencana akan menghafalkan ayat atau surat tertentu di dalam al-Qur'an yang akan dibacakan di dalam akad perniakahan, demikian pendapat Abdus Samad, ${ }^{35}$ Lukman Zahid dan

33 Abu Ishaq Al-Syairazi, Al-Muhazab Fi Fiqh Imam Al-Syafii (Beirut: Dar al-Fikr, 1990).

34 Ahmad bin Abdurrazak al-Duwaisi, Fatawa Al-Lajnah Al-Daimah Li Al-Buhus AlIlmiyah Wa Al-Ifta (Riyad: Dar al-Muayyid, 1409).

35 Teguh Prasetio, "Pendapat Ustaz Abdus Somat Tentang Hafalan Al-Qur'an Dijadikan Mahar," 2018, https://www.tribunnews.com//bolehkah-mahar-pernikahandalam-bentuk-hafalan-al-quran-b egini-penjelasan-us taz-abdul-somad. 
Muhamimin Zen ${ }^{36}$ dalil kalangan penggiat perkumpulan qari-qari dan penghafal al-Qur'an (Jam'iyyat al-Qurra' Wa al-Huffaz).

Maka hukum dari pemberian mahar pernikahan berupa hafalan alQur'an adalah diperbolehkan, karena dianggap tidak bertentangan dengan hukum Islam. Mahar hafalan al-Qur'an juga merupakan wujud dari upaya seorang pria dalam melaksanakan prinsip dan tujuan syariat Islam, yaitu pemeliaharaan kehormatan. Aspek hikmah dari latarbelakang pemberian mahar berupa hafalan al-Qur'an sangat serasi dengan tujuan disyariatkan mahar bagi seseorang yang hendak menikahi wanita.

\section{PENUTUP}

Mahar hafalan al-Qur'an yang banyak terjadi pada masyarakat milenial sekarang ini merupakan fenomena sosial, yang mana pemberian tersebut tidak didasari oleh pemahaman hukum Islam atau fikih munakahat. Motivasi pribadi, kemudahan dalam pemberian mahar dan faktor eksternal lainnya yang mendorong untuk menjadikan hafalan al-Qur'an sebagai mahar pernikahan. Mahar pernikahan berupa hafalan al-Qur'an manakala dianalisis menggunakan kacamata hukum Islam; maqasid syariah, dan Kompilasi Hukum Islam memperoleh titik terang bahwa praktek tersebut masih dalam tataran pembolehan dan tidak bertentangan dengan hukum Islam.

\section{DAFTAR PUSTAKA}

Abdul Wahab Khalaf. 'Ilmu Ushul Al-Fiqh. Cairo: Maktabah Da'wah Islamiyah, 1947.

Abdurrahman. Kompilasi Hukum Islam Di Indonesia. Jakarta: Academia Presindo, 1992.

Abu Bakr Muhammad bin Abdil Mu'min bin Hariz bin Ma'la al-Hasini alHishni. Kifayat Al-Akhyar Fi Halli Ghayat Al-Ikhtishar. Damaskus: Dar alKhair, 1994.

Ahmad bin Abdurrazak al-Duwaisi. Fatawa Al-Lajnah Al-Daimah Li Al-Buhus Al-Ilmiyah Wa Al-Ifta. Riyad: Dar al-Muayyid, 1409.

Al-Kajrati, Jamaluddin Muhammad Tahir bin Ali. Mujma' Bihar Al-Anwar Fi Gharaib at-Tanzil Wa Lataif Al-Akhbar. Vol. 3. Damaskus: Majlis Dairah al-Ma'arif al-Usmaniyah, 1967.

Al-Nawawi, Abu Zakaria Muhyiddin. Raudah At-Thalibin Wa 'Umdah |alMuftin. Beirut: al-Maktabah al-Islami, 1991.

36 Khorul Anam, “Luar Biasa, Mahar Menantu Ketua JQH Berupa Hafalan Al-Qur'an 30 Juz,” 2016, http://www.nu.or.id/post/read/68238/luar-biasa-mahar-menantu-ketumjqh-nu-ini-30-juz-hafalan-al-quran. 
Al-Syairazi, Abu Ishaq. Al-Muhazab Fi Fiqh Imam Al-Syafii. Beirut: Dar al-Fikr, 1990.

Alauddin Abu Bakr bin Mas'ud bin Ahmad al-Kasani. Bada'i Al-Sana'i' Fi Tartib Al-Syara'i. Cairo: Dar al-Kutub al-Alamiyah, 1986.

Ali Muhammad al-Amidi. Al-Ihkam Fi Ushuli Al-Ahkam. Riyad: Dar al-Shami'i Li al-Nasyri Wa al-Tauzi, 2003.

Hamid Abdul Kadir. Al-Mu'jam Al-Wasit. Cairo: Dar ad-Da'wah al-Alamiyah, n.d.

Hermanto, Agus. "Teori Gender Dalam Mewujudkan Ksetaraan:Menggagas Fikih Baru." Ahkam 5 (2017): 209-230.

Jabir bin Musa bin Abdul Qadir Abu Bakr al-Jaza'iri. Aisar Al-Tafasir Li Kalam Al-Aliy Al-Kabir. Madinah al-Munawwarah: Maktabah al-Ulum Wa alHikam, 2003.

Jusmaindah. "Empat Pemuda Ini Menikah Dengan Mahar Hafalan Ayat AlQur'an.” https://makassar.terkini.id/4-pemuda-nikah-mahar-hafalanayat-al-quran/.

(accessed October 26, 2019)

Khorul Anam. "Luar Biasa, Mahar Menantu Ketua JQH Berupa Hafalan AlQur'an 30 Juz," 2016. http://www.nu.or.id/post/read/68238/luarbiasa-mahar-menantu-ketum-jqh-nu-ini-30-juz-hafalan-al-quran. (accesed April 24, 2019)

Kohar, Abd. "Kedudukan Dan Hikmah Mahar Dalam Perkawinan." Hukum Dan Ekonomi Islam, 2016, 42-50.

Muhammad bin Abdullah al-Kharsi. Syarh Mukhtashar Khalil Li Al-Kharsi. Beirut: Dar al-Fikr al-Arabi, 1999.

Muhammad bin Ahmad bi Abi Musa bin Ali al-Hasyimi al-Baghdadi. Al-Irsyad Ila Sabil Al-Rasyad. Muassasah al-Risalah dan Markaz al-Nakhab al'Ilmiyyah, 1998.

Muhammad bin Ahmad bin Sahl al-Sarkhasi. Al-Mabsut. Beirut: Dar alMa'rifah, 1993.

Muhammad bin Ahmad Zainuddin Abu Yahya al-Sinaiki. Fath Al-Wahab Bi Syarh Minhaj Al-Tullab. Beirut: Dar al-Fikr, 1994.

Muhammad bin Idris bin Abbas bin Usaman bin Syafii' bin Abdul Muthalib bin Abdul Manaf al-SyaFi'i. Al-Umm. Beirut: Dar al-Ma'rifah, 1990.

Muhammad bin Mukrim bin Ali, Abu al-Fadl, Jamaluddin Ibnu Manzur. Lisan Al-Arab. Beirut: Dar Shadir, 1414.

Rasyidi, Lili. Hukum Perkawinan Dan Perceraian Di Malaysia Dan Indonesia. Bandung: PT.Remaja Rosdakarya, 1991.

RI, Departeman Agama. Al-Qur'an Dan Terjemahnya. Jakarta: PT. Sinergi Pustaka Indonesia, 2012.

RI, Departemen Agama. Ensiklopedi Islam Di Indonesia. Jakarta: Penerbit Anda 
Utama, 1993.

Rusyd, Muhammad bin Ahmad bin Muhammad bin Ahmad Ibnu. Bidayah AlMujtahid Wa Nihayah Al-Muqtasid. Beirut: Dar Ibn Hazem Li al-Tab'ah Wa Nasyr Wa Tauzi', 2006.

Sa'di Abu Habib. Al-Qamus Al-Fiqhi. Damaskus: Dar al-Fikr al-Arabi, 1988. Syarifuddin, Amir. Hukum Perkawinan Islam Di Indonesia Antara Fikih Munakahat Dan Undang-Undang Perkawinan. Jakarta: Kencana Prenada Media Group, 2009.

Teguh Prasetio. "Pendapat Ustaz Abdus Somat Tentang Hafalan Al-Qur'an Dijadikan Mahar," 2018. https://www.tribunnews.com//bolehkahmahar-pernikahan-dalam-bentuk-hafalan-al-quran-begini-penjelasanustaz-abdul-somad.

(accesed Juni 15, 2019)

Wahbah Mustafa al-Zuhaili. Al-Fiqh Al-Maliki Al-Muyassar. Beirut: Dar alKalim al-Thayyib, 2005.

Wahbah Mustafa al-Zuhaili _-_ . Al-Wajiz Fi Usul Al-Fiqh. Damaskus: Dar al-Fikr, 1999.

Wahbah Mustafa al-Zuhaili _-_. Usul Fiqh Al-Islami. Beirut: Dar al-Fikr, 1986.

Yayasan Qur'an Hamasah. "Alasan Mahar Nikah Hafalan Surat Al-Rahman.” http://hamasahtahfizhnasional.blogspot.com/2016/10/7-alasan-maharnikah-hafalan-surah-ar.html.

(accessed October 20, 2018) 
136 |Ibnu Irawan, Jayusman

---Halaman Ini Sengaja Dikosongkan--- 